\title{
Compactação do solo e macronutrientes primários na Brachiaria brizantha cv. Piatã e Panicum maximum cv. Mombaça
}

\author{
Carlos E. A. Cabral ${ }^{1}$, Edna M. Bonfim-Silva ${ }^{2}$, Emerson A. Bonelli ${ }^{1}$, \\ Tonny J. A. da Silva ${ }^{2}$, Carla H. A. Cabral ${ }^{3} \&$ Walcylene L. M. P. Scaramuzza $^{4}$
}

\begin{abstract}
RESU M O
Os macronutrientes primários possuem papel relevante na adubação de forrageiras, em função da sua participação no custo de produção, razão pela qual se objetivou avaliar os efeitos da compactação na concentração de macronutrientes primários em folhas diagnósticas dos capins Piatã e M ombaça. 0 experimento foi realizado em casa de vegetação, com delineamento inteiramente casualizado, composto de oito tratamentos e três repetições, em esquema fatorial $2 \times 4$, com duas gramíneas (capim-piatã e capim-mombaça) e de quatro densidades do solo $\left(1,0 ; 1,2 ; 1,4\right.$ e 1,6 $\left.\mathrm{M} \mathrm{g} \mathrm{m}^{-3}\right)$. D ois cortes foram realizados, o primeiro aos 42 dias após o desbaste e o segundo 46 dias após o primeiro corte. No primeiro período de crescimento das gramíneas forrageiras a compactação do solo interfere na absorção de nitrogênio e fósforo enquanto no segundo período de crescimento ocorre limitação na absorção de nitrogênio e potássio. 0 nitrogênio é o macronutriente primário mais limitado pela compactação do solo.
\end{abstract}

Palavras-chave: capim-mombaça, capim-piatã, densidade do solo, folha diagnóstica

\section{Soil compaction and primary macronutrients in Brachiaria brizantha cv. Piatã e Panicum maximum cv. Mombaça}

\begin{abstract}
The primary macronutrients have an important role in the forage fertilization, depending on their contribution to the production cost. This paper aimed to evaluate the effects of soil compaction on the concentration of primary macronutrients present in diagnostic leaves of Piatã and Mombaça grasses. The experiment was conducted in a greenhouse with a randomized statistical design, consisting of eight treatments and three replications in $2 \times 4$, factorial scheme, with two grases (Piatã grass and Mombaça) and four soil densities $\left(1.0,1.2,1.4\right.$ and $\left.1.6 \mathrm{M} \mathrm{g} \mathrm{m}^{-3}\right)$. Two harvest of shoots were made, the first 42 days after the plant thinning, and the second 46 days after the first cutting. In the first growing period, the soil compaction interfere with the absorption of nitrogen and phosphorus, while in the second growing period there is a limitation in the absorption of nitrogen and potassium. Nitrogen is the primary macronutrient most limited by soil compaction.
\end{abstract}

Key words: Mombaça grass, Piatã grass, soil bulk density, diagnostic leaf 


\section{INTRODUÇÃO}

A compactação do solo em pastagem é assunto controverso. Por um lado, afirma-se que em áreas em que as gramíneas forrageiras são bem manejadas, é pouco provável que esse fenômeno ocorra, pois a dinâmica de fonte-dreno entre raízes e folhas durante a desfolha (Rodrigues et al., 2008) permite um aumento na porosidade do solo, na mesma proporção em que o pisoteio animal reduz essa propriedade física. Existem evidências de que as gramíneas aumentam a porosidade do solo (Fidalski \& Tormena, 2007).

Por sua vez, Azevedo \& Sverzut (2007) estudaram solos com pastagem no Mato Grosso e perceberam que o pisoteio animal favorece a compactação da camada superficial do solo, evidenciada pelo aumento da densidade do solo e da resistência do solo à penetração e pela diminuição da macroporosidade, da porosidade total e da condutividade hidráulica. Isto culmina em redução da taxa de infiltração e predispõe o solo à erosão. Du Toit et al. (2009) verificaram aumento da densidade e redução da infiltração de água no solo em pastagens intensamente pastejadas por ovinos, enquanto Queiroga et al. (2009) observaram aumento na densidade do solo ao inserir bovinos em pastagens implantadas sob sistemas convencional e plantio direto. Com o aumento da adubação nitrogenada e a intensificação do manejo e pisoteio animal, Sarmento et al. (2008) não observaram redução da densidade do solo, mas redução da macroporosidade e aumento da microporosidade. Independentemente da adubação, a camada de $0-5 \mathrm{~cm}$ apresentou densidade menor que a camada de $0-10 \mathrm{~cm}$. Áreas submetidas ao pastejo durante 20 anos podem apresentar aumento da resistência à penetração, passível de ser 2,6 vezes maior do que é tolerado para o desenvolvimento de raízes (Silva Filho et al., 2010).

A compactação do solo em áreas de pastagens pode limitar a produção das gramíneas forrageiras. A Brachiaria brizantha apresenta desenvolvimento adequado na densidade de $1,2 \mathrm{Mg}$ $\mathrm{m}^{-3}$ (Silva et al., 2006). Com o aumento da densidade do solo o capim-mombaça (Panicum maximum cv. Mombaça) apresenta redução do número de perfilhos, da produção da parte aérea e de folhas enquanto o capim-piatã aponta alteração apenas na massa de colmos (Bonelli et al., 2011). Na Amazônia colombiana Martínez \& Zinck (2004) verificaram aumento da resistência a penetração em 10 vezes, em pastagens de nove anos de implantação em comparação com a vegetação original da área (mata nativa) e redução na produção de matéria seca em $60 \%$, em função da compactação causada pelo pisoteio animal.

A redução na produção das forrageiras pode ser explicada pela limitação na absorção de nutrientes e pela alteração na nutrição mineral. Os macronutrientes primários (nitrogênio, fósforo e potássio) possuem papel importante na adubação de forrageiras em função da sua participação no custo de produção e devido à tolerância das gramíneas forrageiras à acidez. Na implantação se destaca o fósforo, enquanto na manutenção esse papel é desempenhado pelo nitrogênio e pelo potássio. A modificação do balanço de nitrogênio se dá pela alteração do estado de aeração do solo, que contribui para a perda por desnitrificação. Como o fósforo tem pouca mobilidade no solo, o efeito da compactação sobre sua absorção está relacionado à limitação radicular e o potássio possui absorção reduzida com o aumento da densidade do solo. Por outro lado, Rosolem et al. (2002) não verificaram alteração na nutrição mineral de milheto (Pennissetum americanum) e sorgo (Sorghum bicolor) submetidos à compactação subsuperficial, em solos com resistência à penetração da ordem de 1,34 MPa. Miransari et al. (2009) verificaram limitações na nutrição do milho em solo compactado, sugerindo a utilização de micorrizas para atenuar esta condição.

Predominantemente, as gramíneas dos gêneros Panicum e Brachiaria ocupam as pastagens do Cerrado (Braz et al., 2004; Oliveira et al., 2007b) e poucos são os dados na literatura que se referem ao efeito da compactação do solo sobre a absorção de nutrientes., Objetivou-se, então, avaliar a concentração de macronutrientes nas folhas diagnósticas $(+1$ e +2$)$ de capimpiatã (Brachiaria brizantha cv. Piatã) e capim-mombaça (Panicum maximum cv. Mombaça) submetidos à compactação de solo.

\section{Material e MÉTOdos}

O experimento, realizado em casa de vegetação na Faculdade de Agronomia e Medicina Veterinária da Universidade Federal de Mato Grosso (FAMEV), em Cuiabá, MT, foi conduzido sob delineamento experimental inteiramente casualizado, com oito tratamentos e três repetições arranjados em esquema fatorial 2 x 4, que envolvendo duas gramíneas forrageiras, capim-piatã (Brachiaria brizantha cv. Piatã) e capim-mombaça (Panicum maximum cv. Mombaça) e quatro níveis de densidade do solo: 1,$0 ; 1,2 ; 1,4$ e $1,6 \mathrm{Mg} \mathrm{m}^{-3}$. Esses níveis de densidade foram verificados no ensaio com um equipamento Proctor normal, conforme a norma NBR 7182 (ABNT, 1986).

O solo utilizado foi um Latossolo Vermelho Amarelo, apresentando as seguintes características químicas e físicas: $\mathrm{pH}\left(\mathrm{CaCl}_{2}\right): 5,2 ; \mathrm{P}: 20,4 \mathrm{mg} \mathrm{dm}^{-3} ; \mathrm{K}: 94 \mathrm{mg} \mathrm{dm}^{-3} ; \mathrm{Ca}: 2,1 \mathrm{cmol} \mathrm{dm}^{-3}$; $\mathrm{Mg}$ : 1,0 $\mathrm{cmol} \mathrm{dm}^{-3} ; \mathrm{S}: 6,2 \mathrm{mg} \mathrm{dm}^{-3} ; \mathrm{H}: 3,2 \mathrm{cmol}_{\mathrm{c}} \mathrm{dm}^{-3}$; Al: 0,0 $\mathrm{cmol}_{\mathrm{c}} \mathrm{dm}^{-3} ; \mathrm{Zn}^{\mathrm{c}}: \mathrm{mg} \mathrm{dm}^{-3}$, $\mathrm{Cu}: 1,1 \mathrm{mg} \mathrm{dm}^{-3}$; Fe: $257^{\mathrm{c}} \mathrm{mg} \mathrm{dm}^{-3} ; \mathrm{Mn}$ : $78,6 \mathrm{mg} \mathrm{dm}^{-3}$; B: $0,21 \mathrm{mg} \mathrm{dm}^{-3}$; CTC: $6,54 \mathrm{cmol}_{\mathrm{c}} \mathrm{dm}^{-3}$; saturação por bases: $51 \%$; matéria orgânica: $27,8 \mathrm{mg} \mathrm{dm}^{-3}$; areia: $696 \mathrm{~g} \mathrm{~kg}^{-1}$; silte: $66 \mathrm{~g} \mathrm{~kg}^{-1} \mathrm{e}$ argila: $238 \mathrm{~g} \mathrm{~kg}^{-1}$. O solo foi peneirado em malha de $2 \mathrm{~mm}$ antes de ser transferido para as unidades experimentais.

A unidade experimental foi constituída pela sobreposição e encaixe de dois aneis de PVC rígido, com diâmetro de $200 \mathrm{~mm}$ (Figura 1A); o anel superior, com altura de $60 \mathrm{~mm}$ e encaixe macho de $5 \mathrm{~mm}$ nas duas extremidades e o anel inferior com 145 mm de altura, com encaixe fêmea de $5 \mathrm{~mm}$ na extremidade superior (Figura 1B). Na parte inferior da unidade experimental havia uma tela antiafídeos com malha de $1 \mathrm{~mm}$, fixada com anel de borracha obtido pela secção transversal de câmara de ar de motocicleta. No encaixe dos aneis foi realizado um acabamento com fita adesiva.

Os aneis inferiores foram preenchidos com solo com densidade de $1,0 \mathrm{Mg} \mathrm{m}^{-3}$, enquanto os superiores tiveram os mesmos níveis de densidade do solo já citados anteriormente. A massa de solo destinada ao anel superior foi compactada com a utilização de uma prensa hidráulica Charlott PH5T. Para eliminar o espelhamento provocado pela prensa, escarificou- 
A.
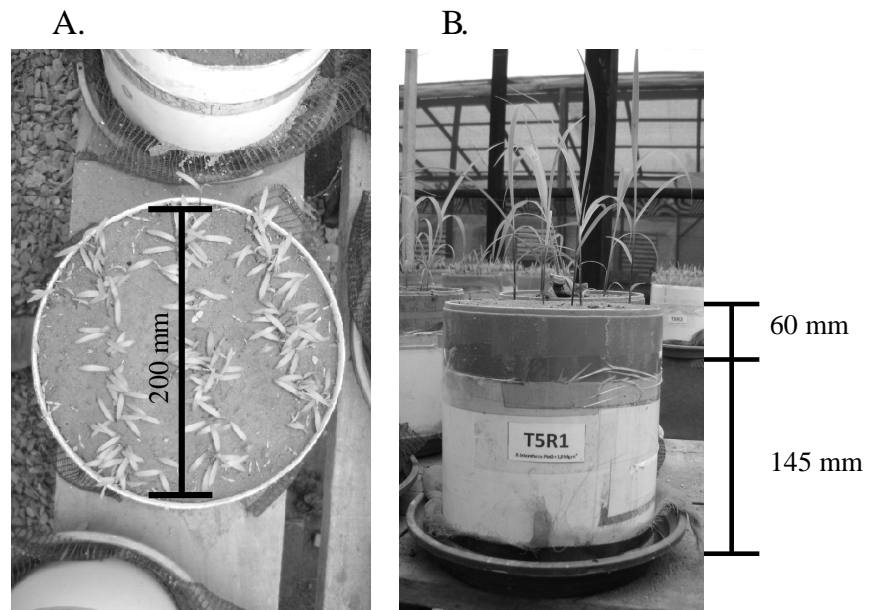

Figura 1. Vista aérea (A) e lateral (B) da parcela experimental composta pela sobreposição de dois anéis rígidos de PVC

se levemente a superfície das amostras, mantendo-se uma camada superior de solo não compactado de $5 \mathrm{~mm}$.

Em cada vaso foram semeadas 15 sementes na profundidade de $5 \mathrm{~mm}$. Sete dias após realizou-se o desbaste mantendo-se cinco plantas por vaso. A umidade do solo foi mantida com base na metodologia proposta por Silva et al. (2006).

Realizou-se uma adubação para o estabelecimento da forrageira utilizando-se nitrogênio, fósforo, potássio e enxofre nas doses de 200, 200, 150 e $20 \mathrm{mg} \mathrm{dm}^{-3}$, utilizando, as seguintes fontes: uréia, superfosfato simples, cloreto de potássio e sulfato de cálcio, respectivamente.

A parte aérea das plantas foi cortada 42 dias após o desbaste e as plantas sofreram cortes a $5 \mathrm{~cm}$ da superfície do solo; em seguida, o material coletado foi separado em lâminas foliares (separando-se as folhas diagnósticas $+1 \mathrm{e}+2$ ) e colmo+bainha, e submetido à secagem em estufa de circulação forçada a $60 \pm$ $5^{\circ} \mathrm{C}$, por $72 \mathrm{~h}$. Este material foi pesado e moído (moinho tipo Willey), em peneiras com porosidade de $1 \mathrm{~mm}$. As folhas diagnósticas foram utilizadas para avaliar a concentração de macronutrientes nas plantas forrageiras pelo método de Sarruge \& Haag (1974); decorridos 46 dias do primeiro corte realizou-se o segundo corte nas plantas, procedendo-se da mesma maneira que no primeiro corte.

Os resultados foram submetidos à análise de variância e, quando significativa, determinou-se a regressão para os níveis de compactação e o teste de Tukey para comparação de médias para as gramíneas forrageiras. Adotou-se 0,05 como nível crítico de probabilidade de erro.

\section{RESULTADOS E DISCUSSÃO}

A compactação do solo interferiu na nutrição mineral dos capins Mombaça e Piatã, haja vista que houve mudança na concentração foliar de macronutrientes nos dois períodos de crescimento das gramíneas forrageiras; no primeiro período houve efeito da compactação sobre a concentração foliar de nitrogênio e fósforo enquanto no segundo período ocorreu efeito sobre a concentração foliar de nitrogênio e potássio. Em ambos os períodos de crescimento verificou-se que a compactação reduz a porosidade do solo e esta, por sua vez, altera a dinâmica de água no solo, que é o meio pelo qual os nutrientes são absorvidos e disponibilizados para o metabolismo vegetal.

No primeiro crescimento constatou-se efeito da compactação sobre a concentração foliar de nitrogênio e um mesmo modelo descreveu a resposta das duas gramíneas forrageiras. A concentração foliar de nitrogênio apresentou comportamento quadrático (Figura 2A) e concentração máxima de $38,08 \mathrm{~g} \mathrm{~kg}^{-1} \mathrm{de}$ nitrogênio na densidade do solo, de $1,28 \mathrm{Mg} \mathrm{m}^{-3}$.

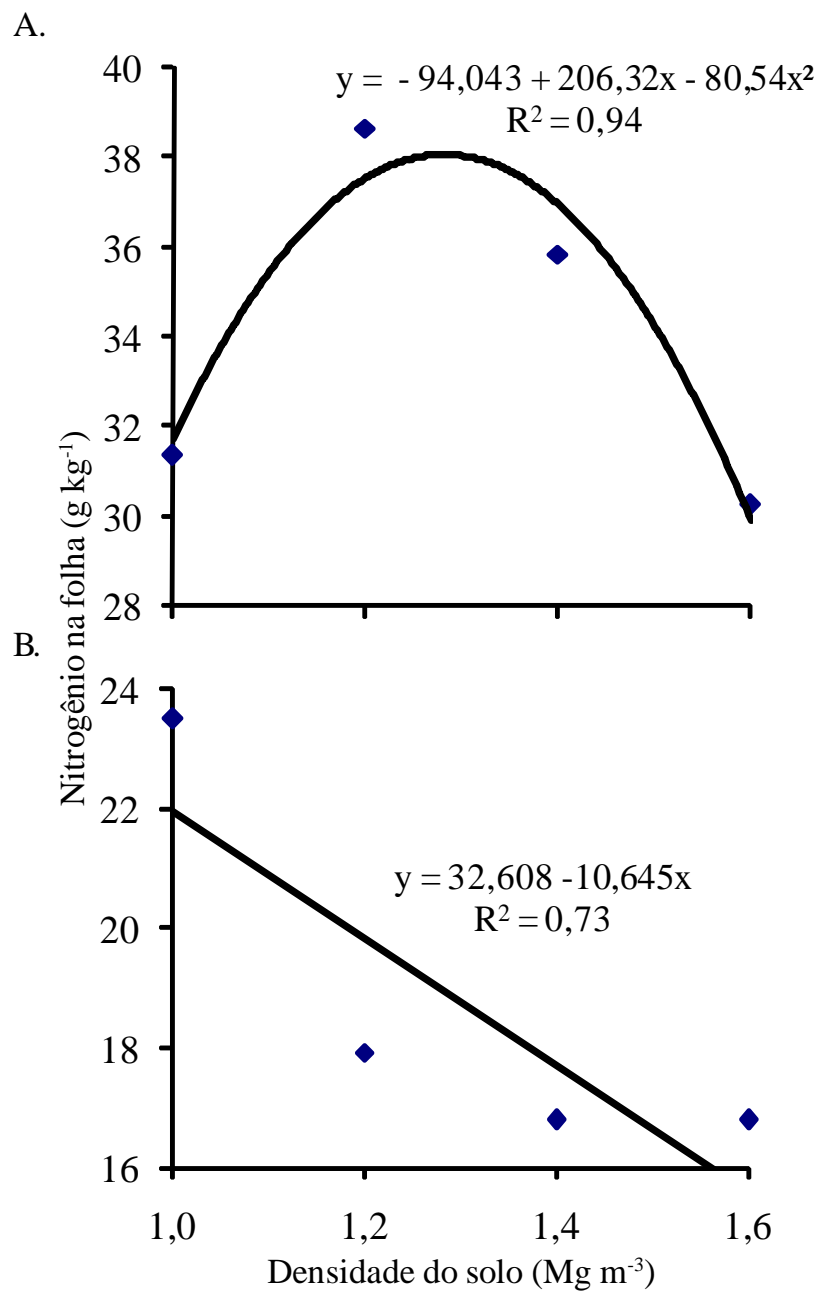

Figura 2. Concentração de nitrogênio nas folhas diagnósticas das forrageiras (A) e do capim-piatã (B), nos primeiro e segundo crescimentos, respectivamente, em resposta à densidade do solo

Em todas as densidades não houve deficiência de nitrogênio, tendo em vista que a concentração de nitrogênio foliar esteve acima do teor que compromete o metabolismo de gramíneas (Oliveira et al., 2007b). Isto acontece porque a redução do diâmetro dos poros do solo aumenta a condutividade hidráulica do solo não saturado (Borges et al., 1999), fenômeno importante no fluxo de massa, principal via de transporte de nitrato no solo (Costa et al., 1999; Rocha et al., 2008). Contudo, a compactação do solo acarreta em perda de nitrogênio do solo, pela emissão de óxido nitroso (Bhandral et al., 2007), ou pelo 
acúmulo de íons amônio (Pengthamkeerati et al., 2006); entretanto, neste experimento tal evento não limitou a implantação das gramíneas pela baixa necessidade de nitrogênio nesse estádio de desenvolvimento (Cantarutti et al., 1999).

No segundo crescimento, entretanto, a interação entre os fatores compactação e espécie forrageira foi notória e apenas para o capim-piatã foi afetada a concentração foliar de nitrogênio, resposta esta descrita por uma regressão linear decrescente (Figura 2B). A maior densidade do solo acarretou em redução de $29 \%$ da concentração de nitrogênio nas folhas do capim-piatã. O nitrogênio é essencial para a síntese protéica, sendo possível que grande parte desse nutriente tenha sido translocada para o desenvolvimento radicular (Silva \& Monteiro, 2010), uma vez que não houve diferença na massa radicular em todas as densidades do solo, e pode ter limitado a concentração nas folhas. Embora o capim-mombaça não tenha sofrido efeito da compactação no segundo corte apresentou, em média, 15,41 $\mathrm{g} \mathrm{kg}^{-1}$ de nitrogênio, concentração inferior à do capim-piatã em todas as densidades. Binghan et al. (2010), observaram redução na absorção de nitrogênio pela cevada na densidade de $1,1 \mathrm{Mg} \mathrm{m}^{-3}$; contudo, quando se aumentou a dose de nitrogênio este efeito desapareceu, demonstrando que a intensificação da adubação amenizou as consequências da compactação e supriu a necessidade de nitrogênio da planta.

No primeiro período de crescimento notou-se interação entre os fatores compactação e gramínea forrageira para a concentração de fósforo nas folhas diagnósticas. Um modelo quadrático descreveu a resposta do capim-piatã a níveis de densidade do solo enquanto um modelo linear descreveu a resposta da concentração foliar de fósforo no capim-mombaça (Figuras 3A e 3B).

$\mathrm{O}$ aumento da densidade do solo acarreta em maior contato entre solo e raiz, o que proporciona maior absorção de fósforo. Como este nutriente se move por difusão, apresenta baixa mobilidade no solo, explicando a faixa crescente de concentração foliar no capim-piatã. Contudo, a redução na absorção de fósforo que ocorreu a partir da densidade de 1,4 $\mathrm{Mg} \mathrm{m}^{-3}$ no capim-piatã e em todos os tratamentos do capimmombaça está, provavelmente, relacionada ao uso desse nutriente para o desenvolvimento radicular, pois não houve diferença entre a massa de raízes em todas as densidades de solo, fato que demonstra que a forrageira prioriza o recurso limitante. Monteiro et al. (1995) observaram maior concentração de fósforo nas raízes que na parte aérea, quando o capimmarandu (Brachiaria brizantha cv. Marandu) foi submetido a uma solução nutritiva com ausência de fósforo, demonstrando que a forrageira priorizou o sistema radicular sob condições de limitação desse nutriente.

O capim-mombaça apresentou maiores concentrações de fósforo que o capim-piatã, até a densidade de $1,4 \mathrm{Mg} \mathrm{m}^{-3 ;} \mathrm{a}$ partir daí, o capim-piatã apresentou concentrações maiores desse nutriente e, desta forma, o capim-piatã possui maior capacidade de absorver o fósforo sob condições físicas limitantes enquanto o capim-mombaça, que apresenta maior massa radicular, acabou absorvendo maior quantidade de fósforo para desenvolvimento de raízes, reduzindo sua translocação para a parte aérea.
A.

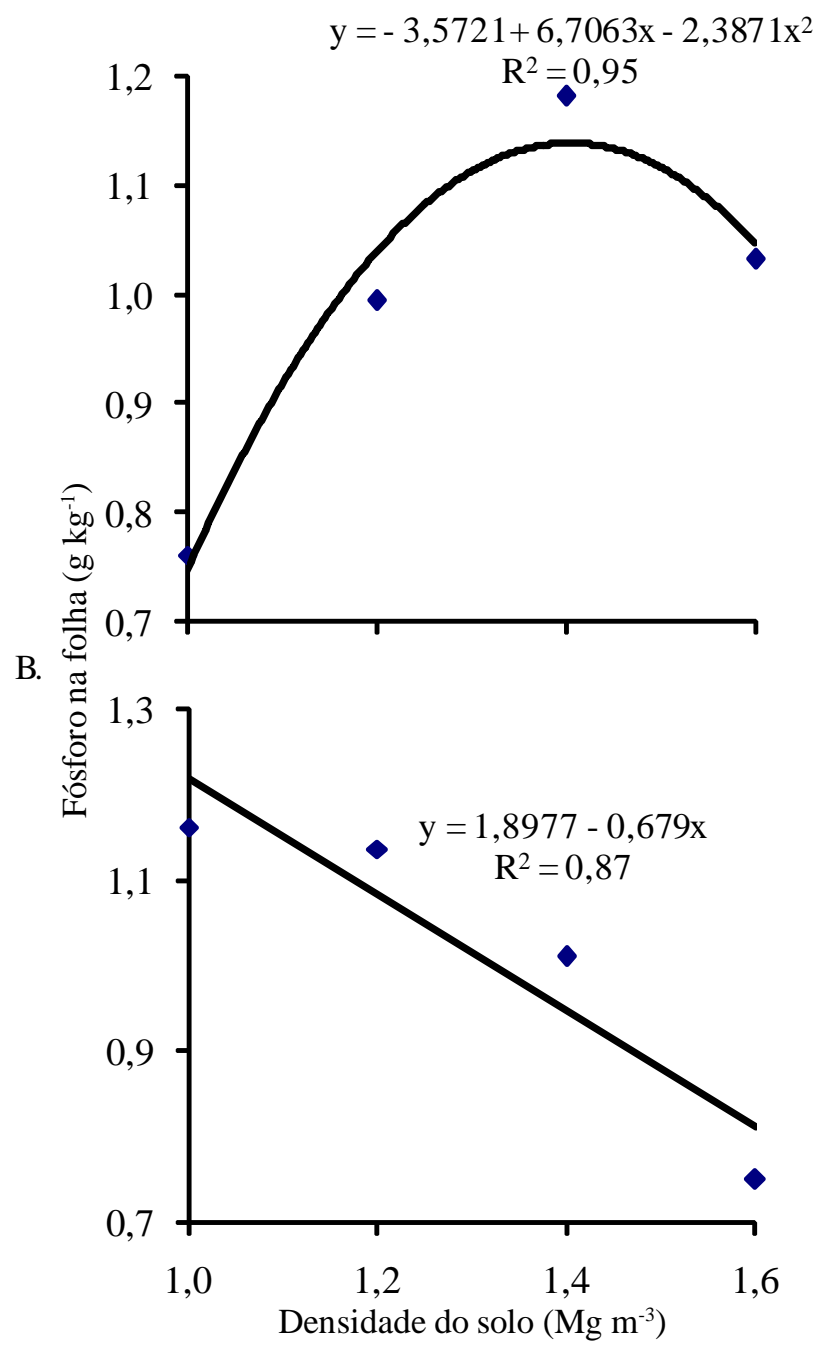

Figura 3. Concentração de fósforo nas folhas diagnósticas do primeiro crescimento do capim-piatã (A) e capimmombaça $(B)$ em resposta à compactação do solo

Observou-se a deficiência nutricional em fósforo apenas nas densidades do solo de 1,0 e 1,6 $\mathrm{Mg} \mathrm{m}^{-3}$, para o capimmombaça e capim-piatã, respectivamente (Oliveira et al., 2007a). Na menor densidade a limitação de contato solo-raiz influenciou, sem dúvida, a absorção de fósforo. Por outro lado, o aumento da densidade do solo causa redução no fluxo difusivo (Costa et al., 1999), o que pode ter limitado a absorção de fósforo nas maiores densidades do solo.

A concentração foliar de fósforo não foi afetada pela compactação no segundo crescimento nem na interação entre os fatores. Ocorreu diferença na concentração de fósforo nas folhas diagnósticas, nas quais os capins Piatã e Mombaça apresentaram 0,46 e $0,28 \mathrm{~g} \mathrm{~kg}^{-1}$. O fósforo é o nutriente mais exigido no estabelecimento da cultura. Na rebrota, a necessidade desse nutriente é reduzida, sendo este o motivo da compactação não ter influenciado a dinâmica desse nutriente no segundo crescimento (Cantarutti et al., 1999).

Não houve efeito da compactação sobre as concentrações foliares de potássio no primeiro crescimento. O potássio é um nutriente pouco requerido na implantação de forrageiras e, embora a redução da densidade proporcione limitação na 
absorção radicular, a baixa necessidade desse nutriente foi suprida, mesmo sob a pior condição de compactação do solo. Os capins piatã e mombaça apresentaram concentrações de potássio nas folhas diagnósticas de 25,38 e 18,51 $\mathrm{g} \mathrm{kg}^{-1}$, respectivamente. Essas concentrações de potássio são adequadas para o desenvolvimento de gramíneas que devem possuir, na parte aérea, de 12 a $30 \mathrm{~g} \mathrm{~kg}^{1}$ (Oliveira et al., 2007a).

No segundo crescimento constatou-se efeito na concentração de potássio na folhas de ambas as forrageiras, descrito por uma regressão linear decrescente (Figura 4). Da maior para a menor densidade a redução foi de $61 \%$ na concentração foliar de potássio sendo que, a partir da densidade de $1,4 \mathrm{Mg} \mathrm{dm}^{-3}$ as concentrações foliares já demonstram deficiência desse nutriente.

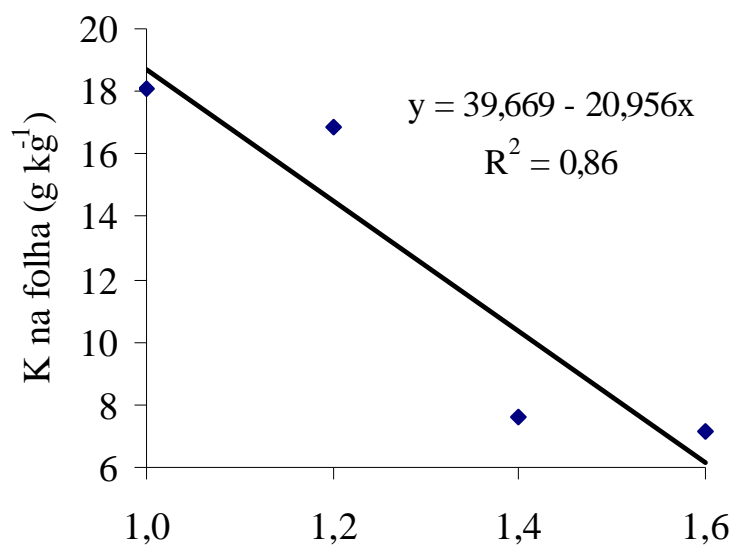

Densidade do solo $\left(\mathrm{Mg} \mathrm{m}^{-3}\right)$

Figura 4. Concentração de potássio nas folhas diagnósticas do segundo crescimento de gramíneas tropicais em resposta à compactação do solo

Em geral, na rebrota de gramíneas forrageiras a necessidade de potássio é aumentada, em razão do crescimento intenso, o que justifica o fato da concentração foliar ter reduzido com o aumento da densidade na rebrota e não na implantação (Rodrigues et al., 2008).

Dos macronutrientes primários o nitrogênio é o único cuja absorção foi limitada em ambos os períodos de crescimento. Embora o nitrogênio seja mais requerido na rebrota (Werner et al., 1997; Cantarutti et al., 1999), é relevante na implantação. Monteiro et al. (1995) inferiram que no primeiro crescimento a massa seca da parte aérea e das raízes e o número de perfilhos do capim-marandu cultivado sem nitrogênio em solução nutritiva representaram, respectivamente, 0,$56 ; 1,69$ e $20 \%$ do que foi produzido pela gramínea em solução nutritiva completa. A relevância no nitrogênio na implantação de gramíneas forrageiras é pouco percebida pelo fornecimento desse nutriente por meio da matéria orgânica do solo (Costa et al., 2008).

\section{Conclusões}

1. No primeiro período de crescimento dos capins piatã e mombaça a compactação interfere na absorção de nitrogênio e fósforo, enquanto no segundo período de crescimento há limitação na absorção de nitrogênio e potássio.

2. O macronutriente primário mais limitado pela compactação é o nitrogênio.

\section{LITERATURA CITADA}

ABNT - Associação Brasileira de Normas Técnicas. NBR 7182: Solo. Ensaio de compactação. NBR 3. Rio de Janeiro: ABNT, 1986. 11p.

Azevedo, E. C.; Sverzut, C. B. Alterações dos atributos físicos e químicos do solo sob pastagem no sudoeste do estado de Mato Grosso. Revista Agricultura Tropical, v.9, p.1-17, 2007.

Bhandral, R.; Saggar, S.; Bolan, N. S.; Hedley, M. J. Transformation of nitrogen and nitrous oxide emission from grassland soils as affected by compaction. Soil \& Tillage Research, v.94, p.482-492, 2007.

Binghan, I. J.; Bengough, A. G.; Rees, R. M. Soil compaction N interactions in barley: Root growth and tissue composition. Soil \& Tillage Research, v.106, p.241-246, 2010.

Borges, E.; Antonino, A.C.D.; Dall'Olio, A.; Audry, P.; Carneiro, C.J.G. Determinação da condutividade hidráulica e da sorvidade de um solo não-saturado utilizando-se permeâmetro a disco. Pesquisa Agropecuária Brasileira, v.34, p.2083-2089, 1999.

Braz, A. J. B. P.; Silveira. P. M.; Kliemann, H. J.; Zimmermann, J. P. Acumulação de nutrientes em folhas de milheto e dos capins braquiária e mombaça. Pesquisa Agropecuária Tropical, v.34, p.83-87, 2004.

Bonelli, E. A.; Silva, E. M. B.; Cabral, C. E. A.; Campos, J. J.; Scaramuzza, W. L. M. P.; Polizel, A. C. Compactação do solo: Efeitos nas características produtivas e morfológicas dos capins piatã e mombaça. Revista Brasileira de Engenharia Agrícola e Ambiental, v.15, p.264-269, 2011.

Cantarutti, R. B.; Martinez, H. E. P., Carvalho, M. M.; Fonseca, D. M.; Arruda, A. L.; Vilela, H.; Oliveira, F. T. T. Pastagens. In: Ribeiro, A. C.; Guimarães, P. T. G. Alvarez V., V. H., eds. Recomendação para o uso de corretivos e fertilizantes em Minas Gerais. $5^{\text {a }}$ aproximação. Viçosa: CFSEMG, 1999. p.4360

Costa, K. A. P. P.; Faquin, V.; Oliveira, I. P.; Rodrigues, C.; Severiano, E. C. Doses e fontes de nitrogênio em pastagem de capim-marandu. I - alterações nas características químicas do solo. Revista Brasileira de Ciência do Solo, v.32, p.15911600, 2008.

Costa, S. N.; Martinez, M. A.; Matos, A. T.; Ramos, V. B. N. Mobilidade de nitrato em colunas de solo sob condições de escoamento não permanente. Revista Brasileira de Engenharia Agrícola e Ambiental, v.3, p.190-194, 1999.

Du Toit, G. van N.; Snyman, H. A.; Malan, P. J. Physical impact of grazing by sheep on soil parameters in the Nama Karoo subshrub/grass rangeland of South Africa. Journal of Arid Environments, v.73, p.804-810, 2009.

Fidalsk, J.; Tormena, C. A. Homogeneidade da qualidade física do solo nas entrelinhas de um pomar de laranjeira com sistemas de manejo da vegetação permanente. Revista Brasileira de Ciência do Solo, v.31, p.637-645, 2007. 
Martínez, L. J.; Zinck, J. A. Temporal variation of soil compaction and deterioration of soil quality in pasture areas of Colombian Amazonia. Soil \& Tillage Research, v.75, p.3$17,2004$.

Miransari, M.; Bahrami, H. A; Rejali, F.; Malakouti, M. J. Effects of soil compaction and arbuscular mycorrhiza on corn (Zea mays L.) nutrient uptake. Soil \& Tillage Research, v.103, p.282-290, 2009.

Monteiro, F. A.; Ramos, A. K. B.; Carvalho, D. D. de; Abreu, J. B. R.; Daiub, J. A. S.; Silva, J. E. P.; Natale, W. Cultivo de Brachiaria brizantha Stapf. cv. Marandu em solução nutritiva com omissões de macronutrientes. Scientia Agrícola, v.52, p.135-141, 1995.

Oliveira, P. P. A.; Marchesin, W.; Luz, P. H. C.; Herling, V. R. Guia de identificação de deficiências nutricionais em Brachiaria brizantha cv. Marandu. São Carlos: Embrapa Pecuária Sudeste, 2007a. 38p. Comunicado Técnico, 76

Oliveira, T. K.; Macedo, R. L. G.; Santos, I. P. A.; Higashikawa, E. M.; Venturin, N. Produtividade de Brachiaria brizantha (Hochst. ex A. Rich.) Stapf cv. marandu sob diferentes arranjos estruturais de sistema agrossilvipastoril com eucalipto. Ciência e Agrotecnologia, v.31,p.748-757, 2007b.

Pengthamkeerati, P.; Motavalli, P. P.; Kremer, R. J.; Anderson, S. H. Soil compaction and poultry litter effects on factors affecting nitrogen availability in a claypan soil. Soil \& Tillage Research, v.91, p.109-119, 2006.

Queiroga, A.; Fernández, R.; Noellemeyer, E. Grazing effect on soil properties in conventional and no-till systems. Soil \& Tillage Research, v.105, p.164-170, 2009.

Rocha, F. A.; Martinez, M. A.; Matos, A. T.; Cantarutti, R. B.; Silva, J. O. Modelo numérico do transporte de nitrogênio no solo. Parte II: Reações biológicas durante a lixiviação. Revista Brasileira de Engenharia Agrícola e Ambiental, v.12, p.54-61, 2008.
Rodrigues, R. C.; Mourão, G. B.; Brennecke, K.; Luz, P. H. C.; Herling, V. R. Produção de massa seca, relação folha/colmo e alguns índices de crescimento do Brachiaria brizantha cv. Xaraés cultivado com a combinação de doses de nitrogênio e potássio. Revista Brasileira de Zootecnia, v.37, p.394-400, 2008.

Rosolem, C. A.; Foloni, J. S. S.; Tiritan, C. S. Root growth and nutrient accumulation in cover crops as affected by soil compaction. Soil \& Tillage Research, v.65, p.109-115, 2002.

Sarmento, P.; Rodrigues, L. R. A.; Cruz, M. C. P.; Lugão, S. M. B.; Campos, F. P.; Centurion, J. F.; Ferreira, M. E. Atributos químicos e físicos de um Argissolo cultivado com Panicum maximum Jacq. cv. IPR-86 milênio, sob lotação rotacionada e adubado com nitrogênio. Revista Brasileira de Ciência do Solo, v.32, p.183-193, 2008.

Sarruge, J. R.; Haag, H. P. Análise química em plantas. Piracicaba: Departamento de Química/ESALQ, 1974. 56p.

Silva, E. M. B.; Monteiro, F. A. Nitrogênio e enxofre na adubação e em folhas diagnósticas e raízes do capimbraquiária em degradação. Revista Brasileira de Zootecnia, v.39, p.1641-1649, 2010.

Silva Filho, E. P.; Cottas, L. R.; Marini, G. B. S. Avaliação da compactação dos solos em áreas de pastagens e florestas em Porto Velho-Rondônia. Boletim de Geografia, v.28, p.145$155,2010$.

Silva, G. J.; Maia, J. C. S.; Bianchini, A. Crescimento da parte aérea de plantas cultivadas em vaso, submetidas a irrigação subsuperficial e a diferentes graus de compactação de um Latossolo Vermelho-escuro distrófico. Revista Brasileira de Ciência do Solo, v.30, p.31-40, 2006.

Werner, J. C.; Paulino, V.T.; Cantarella, H.; Andrade, N. O.; Quaggio, J. A. Forrageiras. In: Raij, B. Van; Cantarella, H.; Quaggio, J.A. Furlani, A. M. C.(ed.) Recomendações de adubação e calagem para o Estado de São Paulo. 2.ed. Campinas: Instituto Agronômico, 1997.p.263-273. Boletim Técnico, 100 